\title{
Leadership and Employees' Innovative Work Behavior: Test of a Mediation and Moderation Model
}

\author{
Francoise Contreras ${ }^{1}$, Juan C. Espinosa1, Utz Dornberger ${ }^{2} \&$ Yonni Angel Cuero Acosta ${ }^{2}$ \\ ${ }^{1}$ School of Management, Universidad del Rosario, Bogotá, Colombia \\ ${ }^{2}$ SEPT, Universität Leipzig, Leipzig, Germany \\ Correspondence: Francoise Contreras, School of Management, Universidad del Rosario, Bogotá, Colombia. Tel: \\ 057-2970200. E-mail: francoise.contreras@urosario.edu.co
}

\author{
Received: July 13, $2017 \quad$ Accepted: July 24, $2017 \quad$ Online Published: August 25, 2017 \\ doi:10.5539/ass.v13n9p9 URL: https://doi.org/10.5539/ass.v13n9p9
}

\begin{abstract}
The aim of this study is to determine the relationship between Transformational (TFL)/ Transactional (TSL) leadership and employees' Innovative Work Behavior (IWB), through a mediation and moderation model. The proposed model postulates that Organizational Climate for Innovation (OCI) and Organizational Absorptive Capacity (OAC) exert a mediating role whereas Employees' Work Engagement (EWE) has a moderating effect in such relationship. A total of 267 Colombian workers from different kind of companies completed a reliable battery of questionnaires. The sample was collected through the MBA programs from two recognized universities located in Bogotá, Colombia. Structural equation modeling and hierarchical regression analyses were used to test the proposed model. According to the results, there is a direct and positive relationship between TFL and IWB as was expected. However, contrary to what had been hypothesized, TSL demonstrated to exert the same positive linkage. OCI and OAC showed its mediator effect in the relationship between TFL/TSL and IWB, nevertheless, this effect was less strong than when the relationship between theses variables was direct. On the contrary, EWE does not exert a moderator effect in this relationship as it was posited, but shows a significant and direct relationship with IWB. This research allows assert that leadership influences IWB, either directly or mediated by organizational variables. These results contribute to extent the literature in a scarcely studied field, by testing an empirical model.
\end{abstract}

Keywords: Employees' work engagement, innovative work behaviour, organizational absorptive capacity, organizational climate for innovation, transformational leadership, transactional leadership

\section{Introduction}

Innovation is crucial for the development, the sustainability and the competitiveness of companies in the current economy. Globalization processes and unpredictable changes in market conditions increase the complexity of the demands that the companies have to face (González-Roma, 2008). This contextual condition requires that companies have to be prepared to change permanently, to be flexible and to sense the business environment to achieve a dynamic adaptation to this complex context. For this reason, scholars argue that innovation is the best strategy to allow firms to be more competitive, deal with increasing customer expectations and maintain their position in marketplaces (Fay, Shippton, West, \& Patterson, 2015; Hoch, 2013; Shafie, Siti-Nabiha, \& Tan, 2014; Subramaniam \& Youndt, 2005). Hence, an important theoretical and practical enquiry is to understand how organizations should be led in order to improve their innovation capabilities (Hoch, 2013) making the firms more competitive and more likely to survive in a highly complex business world. In doing so, the firms' innovation capabilities depends - to an important extent - on the companies' workers abilities. This means, which at the individual level is relevant to study the Innovative Work Behaviour (IWB) in order to understand how innovation can be enhanced within the organizations. In this regard, some studies have found that leadership practices exert some influence on this employees' behaviour as well as other organizational variables. However, in spite of these recent findings, the results are still inconclusive and even in some cases, are opposite.

We argue that this situation could be related to several issues, among them; the complexity of IWB as individual behavior linked to an organizational variables not completely studied, the lesser attention that this concept has received in the innovation field, cultural issues scarcely studied, diverse methodological approaches that avoid to compare results, studies limited to few variables and scarcity of more integrated models that allow to understand 
the IWB as an complex organizational phenomena. Regarding this issue, this research seeks to contribute to this field by proposing and testing an IWB model, based on variables that have shown some relationship with employee's innovative behavior. In this model, transformational and transactional leadership (TFL/TSL) styles might influence the IWB directly or through a mediator or moderator variables, both at the organizational and the individual's level.

It is clear that employees' innovative capacity is not an isolated behavior as it goes beyond to personal traits. There is evidence regarding some factors that exert influence on employees' innovative behavior, especially, those that involve managerial and organizational issues (Pieterse, Van Knippenberg, Schippers, \& Stam, 2010). This employees' behavior arises under determined conditions of the organizational context whose characteristics can potentially inhibit or encourage the innovative behavior in its employees. Accordingly, we proposed a hypothetical conceptual model where leadership practices might influence IWB in a direct way or mediate by two organizational variables: Organizational Climate for Innovation (OCI) and Organizational Absorptive Capacity (OAC). At the same time, we propose that Employees' Work Engagement (EWE) moderates the relationship between leadership and IWB at the individual level.

In the next section, the theoretical framework of the IWB model is given. We provide an overview of the literature related to the variables under study and the propound relationships among them. Then, according to the proposed model, we formulate our hypotheses. After that, we explain the research methodology and outcomes of the analysis. We apply a Structural Equation Modeling (SEM) to analyze the model structure, testing the hypothesized relationships among variables. Finally, we discuss our findings and suggest further studies, ending with practical implications for the management field.

\subsection{Innovative Work Behavior (IWB)}

Innovation is not only a concept related to producing new products or services, but also it is a wider notion addressed to the generation of new processes or practices into the organizational context that benefits the consumers (Shin \& Zhou, 2003). As a process, innovation involves novelty, creativity, research, and organizational tendency to support new ideas to achieving competitive advantages in dynamic contexts (Khan, Nawaz, \& Khan, 2015). Likewise, at the individual level, innovation can be understood as a process developed, transmitted, and transformed by individuals, work teams or networks, at different levels of the organization (Axtell, Holman, \& Wall, 2006; King \& Anderson, 2002). In this context, from the individual approach of innovation, the concept of Innovative Work Behavior (IWB) arises as a critical concept for competitiveness and the companies' long-term survival (George \& Zhou, 2002; Runco, 2004; Scott \& Bruce, 1994), making innovative employees the main asset for today's organizations (De Spiegelaere, Van Gyes, \& Van Hootegem, 2014). However, in spite of its recognized importance and its growing academic interest to understand the organizational and individual variables that underlie the employees' innovation behavior, our knowledge is still limited (Shafie, et al., 2014).

IWB is defined as an employee's action addressed to the generation, application and implementation of new ideas, products, processes, and methods from his or her job position, department unit, or organization. This is an individual and intentional behavior oriented toward the introduction of new useful ideas, processes, procedures, and products (Farr \& Ford, 1990). A few years later, Scott and Bruce (1994) defined this term as a complex behaviour composed by the generation, the promotion and the realization of ideas, all of them considered as behavioural tasks. Similarly, Janssen (2000) defines IWB as "the intentional creation, introduction and application of new ideas within a work role, group or organization, in order to benefit role performance, the group, or the organization" (p.288). Then, De Jong and Den Hartog (2010) assert that IWB is a process composed of four dimensions: exploration, generation, championing, and implementation of ideas. More recently, De Spiegelaere, et al. (2014) describe IWB as an "employee behavior oriented to generation, introduction and application (within a role, group or organization) of ideas, processes, products or procedures, new and intended to benefit the relevant adoption" (p.144). It is necessary to notice that all these definitions are quite similar. There is scholar consensus regarding that IWB is a concept centered in the employee's outcomes through a set of behaviors that are intentional and can be experienced from different levels of the organization.

It is important to distinguish between creativity and IWB, two related notions that frequently tend to overlap each other. Although by definition, innovative behavior involves both, generation and implementation of new ideas (Khan, et al., 2015), some authors assert that innovation is more related to the implementation of ideas whereas creativity might be more related to the generation of ideas. Thus, creativity is a previous process characterized by people's capacity to establish new links between objects, concepts and materials. 


\subsection{Transformational / Transactional Leadership (TFL/TSL) and Innovative Work Behaviour (IWB)}

Leadership concept and the proposed theories around this term have been changing according to paradigms, cultural matters, organizational tendencies, organizational requirements, companies and business context demands among others factors. The organizations of this century have to operate in a globalized and highly competitive world characterized by rapid and unpredictable changes into an uncertain environment. Thus, the necessity to understand the leadership emerges from the companies' need to adjust their operations to the current markets' demands. Likewise, to promote leaders that facilitates permanent organizational changes through their innovative behavior of their employees.

In the proposed model, we chose the transformational and transactional leadership approach due to its robustness and because there is empirical evidence about the relationship between these leadership styles and IWB. However, as was previously pointed out by Kahai, Sosik, and Avolio (2003), and Pieterse et al. (2010), the evidence of this relationship is still scarce and it is crucial to extend the existent literature to provide more empirical findings. Indeed, Pieterse, et al., (2010) point out that our understanding of how leadership practices may influence the employees' innovative behaviour is incipient and this topic should receive more attention from scholars due to its importance for companies today, which should operate in an unpredictable and changing environment. In this context, the employees acquire a relevant role to facilitate the insertion of the companies to this complex context, by promoting permanent changes into the companies, through the innovative behaviors.

As might be expected, due to its features, transformational leadership has shown more evidence about its relationship with IWB than transactional leadership. Transformational leaders strengthen the employees' capacity of achievement by promoting their innovation potential through Inspirational Motivation, Individualized Consideration, Intellectual Stimulation and the self-confidence among the organizational members (DuBrin, 2012; Bass \& Avolio, 2000). Likewise, one of the most important characteristics of transformational leadership is the building of trust between collaborators, organization and leaders who share a common vision and create an organizational collective sense. In addition, this kind of leaders usually have and foster good internal and external communication networks, which joined with a trustful relationship, allow the exchange of knowledge and generate new ideas. This situation is at the core of innovation (Jung, Wu, \& Chow, 2008).

The inspirational motivation, other component of transformational leadership, stimulates and challenges the followers to achieve the organizational goals whereas intellectual stimulation, inspires employees to be more creative and innovative to solve problems (Bass \& Avolio, 2000), promoting an exceptional work performance and a higher tendency to generate new ideas and be more innovate (Ismail, Mohamad, Mohamad, Rafiuddin, \& Zhen, 2010). Lastly, transformational leaders generate commitment in their employees through sharing values, giving an optimistic view and fostering an effective communication among the organizational members promoting an adequate environment to innovate. Thus, transformational leaders are considered as change agents who initiate, implement, and institutionalize new orientations in the organizations with their work teams establishing new practices based on innovative visions and new ideas (Waldman \& Bass, 1991). According to the latter, transformational leadership has been related to organizational innovation processes (Gumusluoglu \& Llsev, 2009; Jung, Chow, \& Wu, 2003) and with Innovative Work Behavior (Afsar, Badir, \& Bin, 2014; Boerner, Eisenbeiss, \& Griesse, 2007; De Jong \& Den Hartog, 2007; Jung et al., 2003; Khan, Aslam, \& Riaz, 2012; Khaola \& Sephelane, 2013; Mumford, Scott, Gaddis, \& Strange, 2002; Pieterse et al., 2010; Waldman and Bass, 1991), although Basu \& Green (1997) found a negative relationship. However, and in spite of this evidence, the findings are still scarce and inconsistent (Pieterse, et al., 2010).

In contrast, transactional leadership has received less attention in relation to innovative behavior, probably because this style of leadership is more task-oriented and toward the maintaining of the stability, characteristics that do not seem to fit with the innovative behavior of employees. However, as it also happens with transformational leadership, the results have been inconclusive. It is important to point out that transactional leadership is characterized by a contingent reward scheme in which the leader reinforces the employees' good performance and punishes their deficient work. In this kind of leadership, the leader indicates how he wants the task to be done through the permanent feedback inhibiting innovative behavior. Pietersen et al., (2010) argued that transactional leadership might have a negative influence on the employees' innovative behaviour because this style is more oriented to the employee's performance than stimulating new and original activities. Coherently, Khaola and Sephelane (2013) found that transactional leadership was negatively related to IWB, whereas Boerner et al., (2007) did not find any relationship. Other authors surprisingly have found that transactional leaders also promote the employees innovative behaviour almost in the same way as transformational leadership. They did not find significant differences between transformational and transactional leadership and concluded 
that both styles of leadership positively predicted IWB (Khan, et al., 2012; Riaz, 2009). It seems that to reinforce and to reward employees' behavior could increase the innovation behavior and improve the quality of their performance (Jung \& Sosik, 2002).

There is a third stance that states that innovative behavior requires combined practices of both, transformational and transactional leadership and that the predominant style will depend on the situation and the contextual characteristics as was stated by Chen and Chen (2007). This is, when technical experience is required for innovation processes, transactional leadership may be more effective but when the innovation processes emphasize in people, it is necessary to exert influence on others through the motivation to achieve common objectives, transformational leadership could be more appropriate, as it takes into account emotions, values, and the beliefs of collaborators. Thus, to combine leadership practices such as to encourage the autonomy, reward the employees' performance, promote clear objectives, and give support, allow the creativity and innovation (Da Costa, Páez, Sánchez, Gondim, \& Rodríguez, 2014; Shafie, et al., 2014). As can be seen, the effect of transformational and transactional leadership on employee's innovative behavior remains unclear due to the scarcity of empirical evidence and because the obtained results have been inconclusive.

Based on the above, this research provides additional evidence regarding the relationship between leadership and employees' innovative behavior, thus our first hypotheses are:

H1a: Transformational Leadership is directly and positively related to employee's Innovative Work Behaviour

H1b: Transactional Leadership is directly and negatively related to employee's Innovative Work Behaviour

It has been asserted that inconclusive findings could be the result of unidentified variables that could moderate the relationship between leadership and IWB (Kahai, et al., 2003; Pieterse, et al., 2010). Pieterse, et al., (2010) suggest that to identify these variables may help to understand more clearly this relationship, therefore, explaining the inconsistent findings. In our model, we propose Employee Work Engagement (EWE) as a moderating variable.

\subsection{Organizational Climate for Innovation (OCI) and Innovative Work Behaviour (IWB)}

The organizational climate for innovation (OCI) is a situational characteristic related to IWB, influencing employee's creativity and implementation of new ideas (Yeoh \& Mahmood, 2013). As in the previous case, the relationship between leadership and IWB could be mediated by organizational variables. We have hypothesized that one of these variables is OCI. A positive socio-emotional climate is quite relevant for creativity, when the working teams share a positive effect, is more likely to have new and novel ideas (De Rivera \& Páez, 2007). In addition, autonomy, security and positive relationships perceived by employees are organizational climate features that increase the innovation capability (Da Costa et al., 2014; Thakur, Hsu, \& Fontenot, 2012). All these characteristics are influenced by the leadership practices. It is important to point out that the organizational climate is a measure of how organizational members experience their organizations. It can be understood as sharing employees' perceptions in relation to the organizational environment, including processes, practices, policies, procedures and behaviors that are rewarded and supported in a company. Also, organizational climate perceptions involve feelings, attitudes, and behavioral tendencies, which make sense and characterize organizational experience (Reichers \& Schneider, 1990).

On its part, the climate for innovation is characterized by norms and organizational practices that value, encourage and reward the changes and innovative initiatives (Scott \& Bruce, 1994). Organizational Climate for Innovation (OCI) is defined as the employees' perception concerning their environment, including a general sense of flexibility to change, recognizing the creativity and providing supplies of resources and time for innovation (Kim \& Yoon, 2015). Also, this environment involves recognition of excellent performance and organizational willingness to experiment with innovative ideas and remarkable tolerance for diversity among their members (Siegel \& Kaemmerer, 1978). This kind of climate requires an environment where creative and innovative approaches are supported and encouraged (Martins \& Terblanche, 2003). It was recently found that the organization that has a strong innovative climate is likely to create new ideas, predicting individual innovation in the companies (Übius, Alas, \& Elenurm, 2013). Martins and Terblanche (2003) highlight the importance to identify which should be these characteristics to improve innovation in the organizations because there is little agreement about them and the reported findings have been inconclusive. In spite of this reduced knowledge, some studies have identified that there are some characteristics that facilitate the IWB: giving comprehensive rewards, allow autonomous work, provide training and work feedback (Hartmann, 2006), support and motivate work teams, promote democratic communication, flexibility and avoid time limits (Dombrowski, Kim, Desouza, Braganza, Papagari \& Baloh, 2007). 
Early studies have indicated that organizational climate factors directly related to work groups increase the innovative behavior in the companies because the IWB emerges in groups of people that share their knowledge (West \& Wallace, 1991). According to this, the quality of interactions between collaborators in the companies for IWB is a crucial topic (Zhou \& Shalley, 2003). Also, it has been observed that the perception of support for organizational innovation and perceived supervisor support was positively related to IWB (Scotth \& Bruce, 1994; James et al., 2008; Martins \& Terblanche, 2003; Janssen, 2005). Recently, Yeoh and Mahmood, (2013) found a significant relationship between the called pro-innovation organizational climates, quality of the interactions between leaders and collaborators and IWB.

In spite of its importance, the knowledge about the relationship between organizational climate and IWB is still limited. As a consequence, there is considerable interest in identifying the organizational conditions that influence such behavior (Damanpour \& Schneider, 2006). We assume that transformational leaders may influence innovative work behavior because this leadership emphasizes in intrinsic rewards, which have shown a relationship with IWB (Judge, Fryxell, \& Dooley, 1997). Extrinsic rewards that are a common practice by transactional leaders seem to be lesser effective to IWB. Thus organizational climate where innovation is valued, employees experience more work satisfaction, find their work more meaningful and have more positive attitudes towards their company (Übius, et al., 2013).

Based on the above mentioned we raise the following hypotheses:

H2a: Organizational Climate mediates the relationship between transformational leadership and Innovative Work Behaviour

H2b: Organizational Climate mediates the relationship between transactional leadership and Innovative Work Behaviour

\subsection{Organizational Absorptive Capacity $(O A C)$ and Innovative Work Behaviour (IWB)}

Organizational Absorptive Capacity (OAC) is currently gaining more interest due to its importance for the survival of companies in an environment highly dependent on change and innovation (Noblet, Simon, \& Parent, 2011). The concept of absorptive capacity emerged in the 1980s in the organizational learning field and is a growing topic of knowledge. Cohen and Levinthal (1990) defined absorptive capacity as the ability to learn from external knowledge through processes of knowledge identification, assimilation, and exploitation. Flatten, Engelen, Shakerand, and Brettel (2011) defined absorptive capacity as the companies' ability to recognize new external knowledge, to assimilate it, and to apply it for commercial purposes. Several authors agree that OAC might effectively impact the organization ability to innovate (Teece, Pisano, \& Shuen, 1997) and this depends on a wide extent on the absorptive capacities of the members of the company, that is to say, employees' innovative behaviour. Absorptive capacity may be related to the individual level and the organizational level. The first case refers to how employees are able to use their own knowledge and mix it with external knowledge. In the second case, organizational level is related to how companies acquire knowledge from external sources and applies it to different levels of the organization in order to produce innovation (Moilanen, Østbye, \& Woll, 2014). For the purpose of this study, this latter approach was assumed.

In a dynamic and turbulent environment, knowledge represents a crucial resource for creating value as well as developing and sustaining competitive advantages (Teece, et al., 1997). Thus, absorptive capacity contributes to the creation and the development of competitive advantages through the management of external knowledge (Camisón \& Forés, 2010) by stimulating strategic management, innovation management and organizational learning (Zahra \& George, 2002). In this last case, both internal and external communication is a source of organizational learning to promote innovation processes (Da Costa et al., 2014). Internal communication is related to sharing information and ideas in the organization, which requires trust and good relationship between the group and organizational members willing to share knowledge, exchange experiences and discuss new ideas. External communication refers to information exchanges with people outside the company to increase the possibility to develop new ideas and make things in a different way. This kind of communication allows acquiring new knowledge and interpreting it in diverse ways, something that is essential for innovation.

The concept of OAC is based on four dimensions widely accepted and validated in several studies (Flatten, Adams, \& Brettel, 2015). Zahra and George, (2002) depicted these dimensions: 1) Acquisition: refers to the identification and intake of external knowledge relevant to the company, 2) Assimilation: the analysis, understanding, and interpretation of the acquired knowledge; 3) Transformation: existing knowledge is combined with the new one updating the routines) and 4) exploitation: this is related to the commercial application of new knowledge. These authors grouped the four dimensions in two categories: Potential Absorptive Capacity (the first two dimensions) and Realized Absorptive Capacity (the last two dimensions) although Realized Absorptive 
Capacity is related to outcomes and performance, both are necessary to obtain exceptional organizational results (Zahra \& George, 2002).

Regarding leadership, the transformational style has been related to absorptive capacity, however, few studies have examined the influence of this leadership on innovation processes, our knowledge about how this influence occurs is still limited (Sattayaraksa \& Boonitt, 2012). On the other hand, Flatten, et al. (2015), found that although transformational leadership shows a greater effect on absorptive capacity, transactional leadership exerts effects as well. Thus, according to these authors, transformational and transactional leadership are related to both the Realize and Potential Absorptive Capacity. These authors concluded that it seems that contingent rewards could exert a positive effect even if the leaders do not share their expectations and goals. Likewise, they confirm the additive effect of these leadership styles on organizational absorptive capacity and highlight the importance to have an adequate balance considering the specific national culture. They included national culture as a moderating variable and found that the impact of transactional leadership on Realized Absorptive Capacity was higher in cultures with high power distance.

H3a: Organizational Absorptive Capacity mediates the relationship between transformational leadership and Innovative Work Behaviour

H3b: Organizational Absorptive Capacity mediates the relationship between transactional leadership and Innovative Work Behaviour

\subsection{Innovative Work Behaviour (IWB) and Employees Work Engagement (EWE)}

Transformational Leadership is related to the employees' engagement (Zhu, Avolio, \& Walumbwa, 2009) by promoting their own capabilities and potential based on the confidence and support they develop with their followers. Following this author's suggestions, this relation should be seen as a dynamic process and because of that, the effect of leaders on employees is not always the same, as it depends on many factors that could exert a moderating effect on this relationship. Regarding the suggestions of the authors previously mentioned, we tested the moderating role of EWE in the relationship between leadership and IWB. Due to the IWB involvement an individual motivational process, we proposed the employees' work engagement as a moderating variable of the relationship between leadership and IWB. It is important to mention that EWE is conceptually similar to intrinsic motivation, which is essential to create and propose something new. Motivated employees trust in their own ability to achieve, dedicate time and energy in their jobs as it happens with engage employees (Salanova \& Schaufeli, 2008). A recent study demonstrates that leadership was related to IWB but mediated by EWE (Gomes, Curral \& Caetano, 2015).

Thus, Individual innovation is manifested when the employees are emotionally involved and motivated with their work because they experience satisfaction and enthusiasm. In other words, when employees are engaged. Work Engagement is defined as a psychological state of involvement, commitment, and attachment related to work (Macey \& Schneider, 2008), a positive affective-emotional state of personal fulfillment and well-being where the employees experience pleasure for their work accompanied by high activation levels (Schaufeli, Salanova, González-Roma, \& Bakker, 2002; Schaufeli \& Bakker, 2004). The engagement has three components; vigor (employees exhibited high levels of energy and they want to dedicate time and effort to their work), dedication (characterized by enthusiasm, inspiration, pride, and challenge at work that they find significant and meaningful) and absorption (evidenced by high concentration while they do something that they find interesting (Schaufeli \& Bakker, 2004). Despite the expected connection between employees work engagement and IWB, there are scarce empirical studies that support this relationship (Park, Song, Yoon, \& Kim, 2014).

Usually, engaged employees give all their capability to solve problems, connect successfully with their partners and develop innovation (Schaufeli \& Bakker, 2004; Hakanen, Perhoniemi, \& Toppinen-Tanner, 2008). It was found that highly engaged employees were more likely to express innovative behaviors than low engaged. Thereby, engaged collaborators have more available personal resources to be involved in innovative behaviors, showing a remarkable performance (Scott \& Bruce, 1994; Shalley \& Gilson, 2004). Thus, work engagement could be seen as both an outcome itself and as an antecedent of behavioral results (Salanova, Agut, \& Peiro, 2005). In spite of being influenced by the organizational environment, EWE is an individual variable that depends on a great extent on how employees feel about their work (Park, et al., 2014). In consequence, EWE was included in our model as an individual variable. In summary, we proposed that engagement moderates the relationship between leadership and IWB.

H4a: Employee Work Engagement moderates the relationship between Transformational Leadership and Innovative Work Behaviour. 
H4b: Employee Work Engagement moderates the relationship between Transactional Leadership and Innovative Work Behaviour.

\section{Method}

We will use Structural Equations Modeling (SEM) analysis through AMOS module of SPSS 20 software. This methodology allows analyzing the mediating and moderating relationships between variables, according to the conceptual proposed model. Our model represents the formulated hypotheses (Figure 1). As can be observed, we propose a direct relationship between leadership transformational/transactional and Innovative Work Behavior (IWB), or a relationship moderated by Employee Work Engagement (EWE) or a relationship mediated by Organizational Climate for Innovation (OCI) and Organizational Absorptive Capacity (OAC). Thus, our proposed model includes both individual (LTF, LTS, EWE and IWB) and organizational variables (OCI and $\mathrm{OAC}$ ) to predict Innovative Work Behaviour.

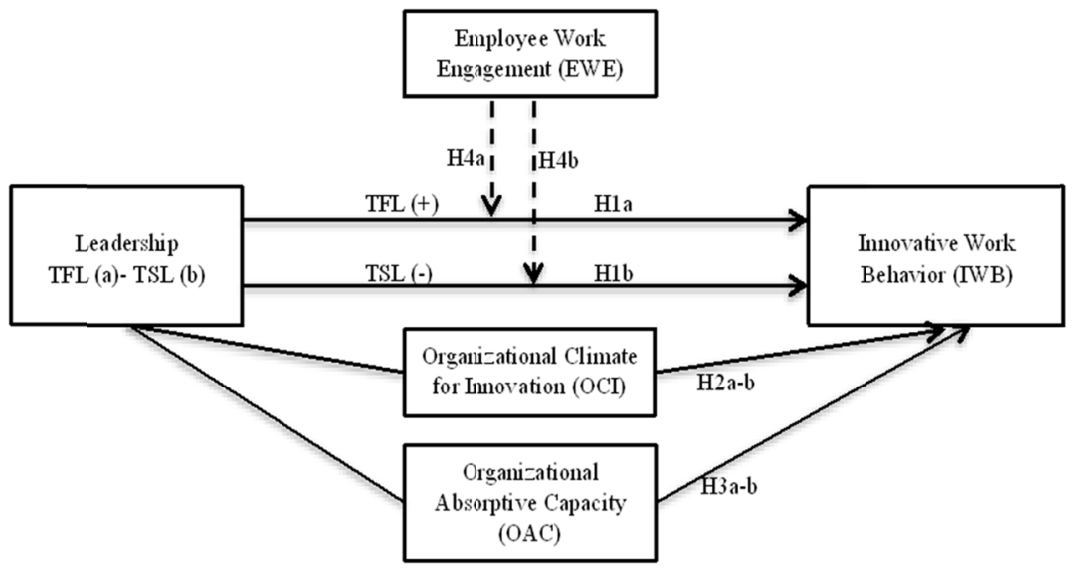

Figure 1. Conceptual model and proposed hypotheses

\subsection{Sample and procedure}

To test the model, a convenient sample of 267 employees was selected from MBA programs in two recognized universities located in Bogotá, Colombia. Almost half of them were women (48\%), and are in the middle age (30-39). Respondents were employees of diverse type of companies that were currently doing their studies of MBA in Colombia. The employee's positions were varied as well. The demographic data of respondents are summarized in Table 1. Surveys were applied both, paper and electronic way. Only employees who had worked with their company for at least one year were allowed to participate. Participants, who completed the surveys, were previously informed about the purposes of the study and they assumed voluntarily to participate in it. Likewise, they were informed about the confidentiality of the information.

\subsection{Measures}

\subsubsection{Innovative Work Behavior Scale}

This scale was designed by Janssen (2000) based on a previous one developed by Scott \& Bruce, (1994) to assess IWB. The scale assesses the individual innovative behaviour in the workplace, through 9-items to be responded in a 7-point scale ranging from 1 to 7 (never and always respectively). The questionnaire evaluates three components of IWB, through three items each one: 1) idea generation, 2) idea promotion, and 3) idea implementation. However, it is considered one-dimensional scale because its subscales have shown strong inter-correlations between them (between .76 and .85). Thus, the subscales are best viewed combined additively, obtaining an overall score of IWB, as have been suggested by several authors (Janssen, 2000; Scott \& Bruce, 1994; De Jong \& Den Hartog, 2008). The Cronbach's alpha is .95 for the whole scale.

\subsubsection{Multifactor Leadership Questionnaire Form 5X (MLQ)}

This questionnaire was elaborated by Bass and Avolio (1995). We select 28 items dedicated to evaluate Transformational Leadership (20) and Transactional Leadership (8). Transformational leadership includes 5 components and has 4 Items for each one. Transactional Leadership includes 2 components and has 4 Items each one. The questionnaire is rated on a five-point scale ranging (From 1 not at all to 5 frequently, if not always). This questionnaire has two forms, leader and collaborator; we use collaborator version, where the leaders are evaluated by their collaborators. The psychometric properties of MQL scale have been demonstrated in several studies. This instrument is reliable, has high validity and its subscales are clearly distinguish one each other. The 
Cronbach's alpha for the whole scale is .84

\subsubsection{Climate for Innovation}

We used the scale proposed by Scott and Bruce (1994) based in Siegel and Kaemmerer (1978). This scale has two factors or separate dimensions of the climate for innovation: 1) Support for innovation, which measures the individual's perception of their organization, whether is open to change, supports new ideas from collaborators and is tolerant to diversity 2) Resource supply, assess the employee's perception about the organizational resources, whether are adequate. This scale is considered the most useful because is oriented directly on organizational support for innovation. This scale has 22 items, 16 for Factor 1 and 6 for factor 2. Cronbach's alpha for Support for Innovation dimension was .92. For the Resource Supply dimension was .77.

\subsubsection{Absorptive Capacity Scale (ACAP)}

This scale was elaborated by Flatten, et al. (2011) and it was designed to evaluate a company's innovation process. Comprise 14 items to evaluate four dimensions: 1) Acquisition: Identification and intake of external knowledge, relevant to the company (3 items), 2) Assimilation: Analysis, understanding, and interpretation of acquired knowledge (4 items), 3) Transformation: Existing knowledge is combined with the new one, updating (4 items) and 4) Exploitation: Commercial application of the new knowledge (3 items) (Zahra \& George, 2002). This conceptualization of Absorptive capacity has been validated in several studies (Flatten, et al., 2015). This scale has demonstrated high reliability in its dimensions. In one research, Flatten, Greve and Brettel (2011) found similar coefficients, (Cronbach's alpha, .73, .85, .93, and .80 respectively). In another study, the whole scale shown high Cronbach's alpha reliability coefficient was .96 and Acceptable convergent validity (Guimaraes, Thielman, Guimaraes \& Cornick, 2016). Finally, the scale has achieved satisfactory reliability for all constructs.

\subsubsection{The Utrecht Work Engagement Scale (UWES)}

UWES Scale was developed by Schaufeli, et al., (2002). This scale comprises 9 items to assess the three engagement dimensions: Vigor, Dedication and Absorption. This scale is scored on a 7-point scale (from never to always). The general UWES scale had good internal consistency (Cronbach's alpha 0.88) and high scores indicate high work engagement.

\section{Results}

\subsection{Descriptive Statistics}

The sample was composed of 267 Colombian workers. The sociodemographic characteristics can be observed in Table 1. The main aspect to highlight is a similar distribution by gender. Almost half of the sample is between 30 and 39 years of age. The participants had manager positions (75.7\%) in large companies with national private capital (63.8\%). More than half of participants work in service sector companies.

Table 1. Descriptive information about participants

\begin{tabular}{|c|c|c|c|c|c|c|c|}
\hline Variable & Category & $f$ & $\%$ & Variable & Category & $f$ & $\%$ \\
\hline \multirow[t]{3}{*}{ Gender } & Male & 138 & 51.9 & Size & $\leq 9$ & 15 & 5.8 \\
\hline & Female & 128 & 48.1 & & $10-19$ & 10 & 3.8 \\
\hline & & & & & $20-49$ & 14 & 5.4 \\
\hline \multirow[t]{6}{*}{ Age } & $20-29$ & 78 & 29.7 & & $50-249$ & 55 & 21.2 \\
\hline & $30-39$ & 130 & 49.4 & & $\geq 250$ & 166 & 63.8 \\
\hline & $40-49$ & 44 & 16.7 & & & & \\
\hline & $50-59$ & 10 & 3.8 & Capital & Public & 71 & 26.6 \\
\hline & $\geq 60$ & 1 & 0.4 & & Private (Nat) & 121 & 45.3 \\
\hline & & & & & Private (For) & 37 & 13.9 \\
\hline \multirow[t]{7}{*}{ Position } & No manager & 64 & 24.3 & & Mix & 34 & 12.7 \\
\hline & Supervisor & 93 & 35.4 & & & & \\
\hline & Manager & 82 & 31.2 & Economic & Primary & 24 & 9.2 \\
\hline & Top manager & 24 & 9.1 & Sector & Secondary & 43 & 16.4 \\
\hline & & & & & Tertiary & 136 & 51.9 \\
\hline & & & & & Government & 54 & 20.6 \\
\hline & & & & & NGO's & 5 & 1.9 \\
\hline
\end{tabular}


Table 2. Shows the scores obtained by the participants in each scale used. According to the results, the questionnaires demonstrated a high reliability (Cronbach's Alpha), both in its dimensions as in its aggregated score (from 0.709 to 0.967 , minimum and maximum respectively).

Table 2. Mean, Standard Deviation, Alpha Reliability Coefficients for the scales used and its dimensions $(\mathrm{N}=$ 267)

\begin{tabular}{|c|c|c|c|c|}
\hline & Mean & Standard Deviation & No. Items & Cronbach's Alpha \\
\hline Innovative Work Behaviour (IWB) & 5.11 & 1.12 & 9 & 0.936 \\
\hline Idealized Influence - Attributed (IA) & 2.76 & 1.03 & 4 & 0.881 \\
\hline Idealized Influence - Behaviour (IB) & 2.85 & 0.91 & 4 & 0.829 \\
\hline Inspirational Motivation (IM) & 2.86 & 1.00 & 4 & 0.909 \\
\hline Intellectual Stimulation (IS) & 2.64 & 0.98 & 4 & 0.846 \\
\hline Individualized Consideration (IC) & 2.63 & 1.00 & 4 & 0.874 \\
\hline Contingent Reward & 2.68 & 0.94 & 4 & 0.814 \\
\hline Management-by-Exception - Active (MBEA) & 2.66 & 0.85 & 4 & 0.803 \\
\hline Transformational Leadership Style & 2.75 & 0.91 & 20 & 0.967 \\
\hline Transactional Leadership Style & 2.67 & 0.82 & 8 & 0.879 \\
\hline Vigor (VI) & 4.78 & 1.15 & 3 & 0.866 \\
\hline Dedication (DE) & 4.94 & 1.18 & 3 & 0.886 \\
\hline Absorption (AB) & 4.65 & 1.16 & 3 & 0.748 \\
\hline Employee Work Engagement & 4.79 & 1.07 & 9 & 0.928 \\
\hline Support for innovation (SP) & 3.03 & 0.67 & 16 & 0.845 \\
\hline Resource Supply (RS) & 2.97 & 0.83 & 6 & 0.709 \\
\hline Climate for Innovation (CIM) & 3.00 & 0.69 & 22 & 0.877 \\
\hline Acquisition (AC) & 4.52 & 1.63 & 3 & 0.862 \\
\hline Assimilation (AS) & 4.35 & 1.58 & 4 & 0.908 \\
\hline Transformation (TR) & 4.50 & 1.50 & 4 & 0.944 \\
\hline Exploitation (EX) & 4.43 & 1.69 & 3 & 0.912 \\
\hline Absorptive Capacity (ACAP) & 4.45 & 1.37 & 14 & 0.950 \\
\hline
\end{tabular}

Note. Range of responses: Innovative Work Behaviour (1 to 7); Leadership factors (0 to 4); Engagement (0 to 6); Climate for innovation (1 to 5); Absorptive Capacity (1 to 7)

\subsection{Hypotheses Test}

Hypotheses 1a, 1b, 2a, 2b, 3a and 3b were tested by six structural equation models (Table 3 ). The table shows different indexes of the fitness models: Chi-square $\left(\chi^{2}\right)$ and both its degrees of freedom $(d f)$ as its probability $(p)$, ratio $\chi^{2} / d f$, Adjusted Goodness of Fit Index (AGFI), Normed Fit Index (NFI), Comparative Fit Index (CFI) and Root Mean Square Error of Approximation (RMSEA). In general terms, the results show a good fit of the models, as can be seen in the Table 3 .

Table 3. Findings from SEM analyses on direct and mediated model analyses

\begin{tabular}{|c|c|c|c|c|c|c|c|c|}
\hline Model & $\begin{array}{c}\chi^{2} \\
(\mathrm{CMIN})\end{array}$ & $d f$ & $p$ & $\begin{array}{l}\text { CMIN } \\
/ \mathrm{DF}\end{array}$ & AGFI & NFI & CFI & RMSEA \\
\hline Reference Value & & & $>0.050$ & $<3.000$ & $>0.950$ & $>0.950$ & $>0.950$ & $<0.080$ \\
\hline \multicolumn{9}{|l|}{ Direct effects } \\
\hline $\mathrm{TFL} \rightarrow \mathrm{IWB}$ & 2.845 & 3 & 0.416 & 0.948 & 0.975 & 0.998 & 1.000 & 0.000 \\
\hline $\mathrm{TSL} \rightarrow \mathrm{IWB}$ & 3.072 & 1 & 0.080 & 3.072 & 0.954 & 0.985 & 0.989 & 0.088 \\
\hline Mediate effects & & & & & & & & \\
\hline
\end{tabular}




\begin{tabular}{lrrrrrrrr}
\hline $\mathrm{TFL} \rightarrow \mathrm{OCI} \rightarrow \mathrm{IWB}$ & 17.208 & 14 & 0.245 & 1.229 & 0.961 & 0.990 & 0.998 & 0.029 \\
$\mathrm{TSL} \rightarrow \mathrm{OCI} \rightarrow \mathrm{IWB}$ & 2,400 & 3 & 0.494 & 0.800 & 0.982 & 0.994 & 1.000 & 0.000 \\
$\mathrm{TFL} \rightarrow \mathrm{ACAP} \rightarrow \mathrm{IWB}$ & 29.989 & 25 & 0.225 & 1.200 & 0.953 & 0.987 & 0.998 & 0.027 \\
$\mathrm{TSL} \rightarrow \mathrm{ACAP} \rightarrow$ IWB & 10,471 & 13 & 0.655 & 0.805 & 0.976 & 0.989 & 1.000 & 0.000 \\
\hline
\end{tabular}

\subsection{Direct effect Hypotheses}

The first hypothesis suggests that leadership has a direct relationship with innovative work behavior. The leadership model used in this research postulates two leadership styles; transformational and transactional leadership whose characteristic are noticeably different. H1a postulates a direct and positive relationship between TFL and IWB, whereas H1b proposes a direct and negative relationship between TSL and IWB. As shown in Figure 2 TFL and TSL exerts a significant effect on IWB $(p<0.001)$, direct and positive. Thus H1a is supported while $\mathrm{H} 1 \mathrm{~b}$ is rejected, TSL does not have a negative relationship with IWB. However, it is important to notice that both leadership styles have positive and significant relationship with IWB.

\subsection{Mediation Analyses Hypotheses}

$\mathrm{H} 2$ and $\mathrm{H} 3$ posited that the relationship between leadership (TFL and TSL) and innovative work behavior is mediated by organizational climate for innovation (OCI) and absorptive capacity respectively. To test these hypotheses, we perform a separate analysis for TFL and TSL for each of them; after that we carry out a Sobel test to probe the mediation effect (Preacher \& Hayes, 2004).

In this regard, $\mathrm{H} 2 \mathrm{a}$ and $\mathrm{H} 2 \mathrm{~b}$ are supported based on two mediated relationships:

$$
\begin{aligned}
& \mathrm{H} 2 \mathrm{a}: \mathrm{TFL} \rightarrow \mathrm{OCI}=0.63^{* * *} \text { and } \mathrm{OCI} \rightarrow \mathrm{IWB}=0.31^{* * *} \text { then } \mathrm{TFL} \rightarrow \mathrm{OCI} \rightarrow \mathrm{IWB}=0.19^{* * *}(\mathrm{a}) \\
& \mathrm{H} 2 \mathrm{~b} . \mathrm{TSL} \rightarrow \mathrm{OCI}=0.57^{* * *} \text { and } \mathrm{OCI} \rightarrow \mathrm{IWB}=0.40^{* * *} \text { then } \mathrm{TSL} \rightarrow \mathrm{OCI} \rightarrow \mathrm{IWB}=0.23^{* * *}(\mathrm{~b})
\end{aligned}
$$

Note: Sobel test for mediation relationship: (a) 3.941; (b) 4.087 ; *** p. $<0.001$

According to this result we accepted the hypotheses $2 \mathrm{a}$ and $2 \mathrm{~b}$. This means that OCI exerts a mediation role between both TFL/TSL and IWB. However, it is important to note that the effect is greater when these variables are directly related.

Regarding the $\mathrm{H} 3$, the mediator effect of AC on the relationship between leadership and IWB, we conduct two separate analyses for each leadership style (TFL and TSL), H3a and H3b respectively. The results support both hypotheses as follows:

$$
\begin{aligned}
& \mathrm{H} 3 \mathrm{a}: \mathrm{TFL} \rightarrow \mathrm{AC}=0.64^{* * *} \text { and } \mathrm{AC} \rightarrow \mathrm{IWB}=0.49^{* * *} \text { then } \mathrm{TFL} \rightarrow \mathrm{AC} \rightarrow \mathrm{IWB}=0.31^{* * *}(\mathrm{c}) \\
& \mathrm{H} 3 \mathrm{~b} . \mathrm{TSL} \rightarrow \mathrm{AC}=0.62^{* * *} \text { and } \mathrm{AC} \rightarrow \mathrm{IWB}=0.48^{* * *} \text { then } \mathrm{TSL} \rightarrow \mathrm{AC} \rightarrow \mathrm{IWB}=0.30^{* * *}(\mathrm{~d})
\end{aligned}
$$

Note: Sobel test for mediation relationship: (c) 5.596 ; (d) $5.305 ; * * *$ p. $<0.001$

These results allow us to accept both hypotheses ( $3 \mathrm{a}$ and $3 \mathrm{~b}$ ). This means that AC has a mediator effect in the relationship between TFL/TSL and IWB. However, it is important to considerer that this effect is smaller in both cases. Likewise, it is important to point out that there are no differences between the two leadership styles assessed. Contrary to OCI, as a mediator variable, AC increases slightly the effect of the leadership over IWB.

\subsection{Moderation Analyses Hypotheses}

Hypotheses $\mathrm{H} 4 \mathrm{a}$ and $\mathrm{H} 4 \mathrm{~b}$ suggested that work engagement moderates the relationship between each style of leadership (TFL / TSL) and IWB. Thus, to test these hypotheses we conduct several hierarchical regression analyses (Hair, Anderson, Tatham, \& Black, 1995). According to the results, we did not find this moderation effect neither TFL nor TSL (Table 4). In other words, EWE does not exert any moderation effect in the relationship between both styles of leaderships and IWB; thus, the hypotheses $\mathrm{H} 4 \mathrm{a}$ and $\mathrm{H} 4 \mathrm{~b}$ are rejected (Figure 2). Nevertheless, it is important to indicate that there is a significant relationship between EWE and IWB.

Table 4. Findings of hierarchical regression analysis with IWB as dependent variable, TFL/TSL as independent variable and EWE as moderator variable.

\begin{tabular}{ccccccc}
\hline & Step 1 & $p$. & Step 2 & $p$. & Step 3 & $p$. \\
\hline TFL & 0.288 & 0.000 & 0.055 & 0.367 & 0.052 & 0.396 \\
EWE & - & - & 0.470 & 0.000 & 0.435 & 0.000 \\
TFL * EWE & - & - & - & - & -0.065 & 0.315 \\
Adjusted R-square & 0.079 & 0.000 & 0.244 & 0.000 & 0.244 & 0.000 \\
\hline
\end{tabular}




\begin{tabular}{ccccccc}
\hline & Step 1 & $p$. & Step 2 & $p$. & Step 3 & $p$. \\
\hline R Square Change & - & - & 0.167 & 0.000 & 0.003 & 0.315 \\
TSL & 0.267 & 0.000 & 0.025 & 0.681 & 0.025 & 0.690 \\
EWE & - & - & 0.485 & 0.000 & 0.445 & 0.000 \\
TSL * EWE & - & - & - & - & -0.071 & 0.276 \\
Adjusted R-square & 0.068 & 0.000 & 0.242 & 0.000 & 0.243 & 0.000 \\
R Square Change & - & - & - & - & 0.003 & 0.276 \\
\hline
\end{tabular}

Panel A

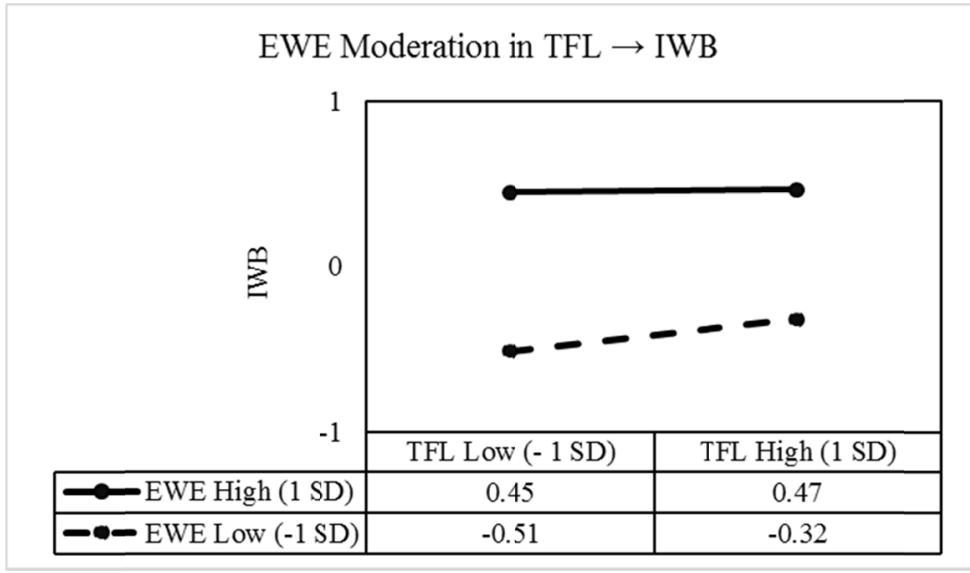

Panel B

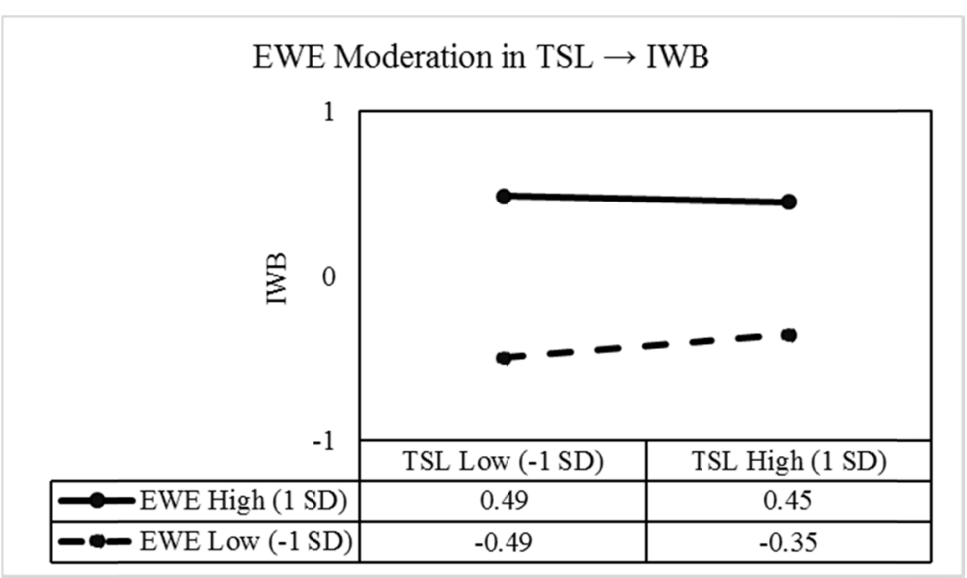

Figure 2. Moderation effect of employee work engagement (EWE) in the relationship between leadership styles and innovative work behavior (IWB).

In order to assess our proposed conceptual model, we summarize the empirical results of the hypotheses put forward. In the Figure 3 one can see all the relationships proposed among the variables included in the model. Firstly, we found a direct effect of the leadership styles (transformational and transactional) on innovative work behavior; both styles exert a similar influence of such behavior (H1a accepted and H1b rejected), contrary to what we had hypothesized. Secondly, the mediated relationships proposed received support; the results suggest evidence of a mediated relationship of organizational climate for innovation and absorptive capacity in the relationship between both styles of leadership and innovative work behavior (H2a-b and H3a-b accepted), it is stronger in the case of the absorptive capacity than organizational climate for innovation. Finally, but not least important, the employees' work engagement does not have a significant moderation effect in the relationship between both style of leadership and innovative work behavior (H4a and H4b rejected); however, it was found a significant and positive relationship between engagement and innovative work behavior (direct effect). 


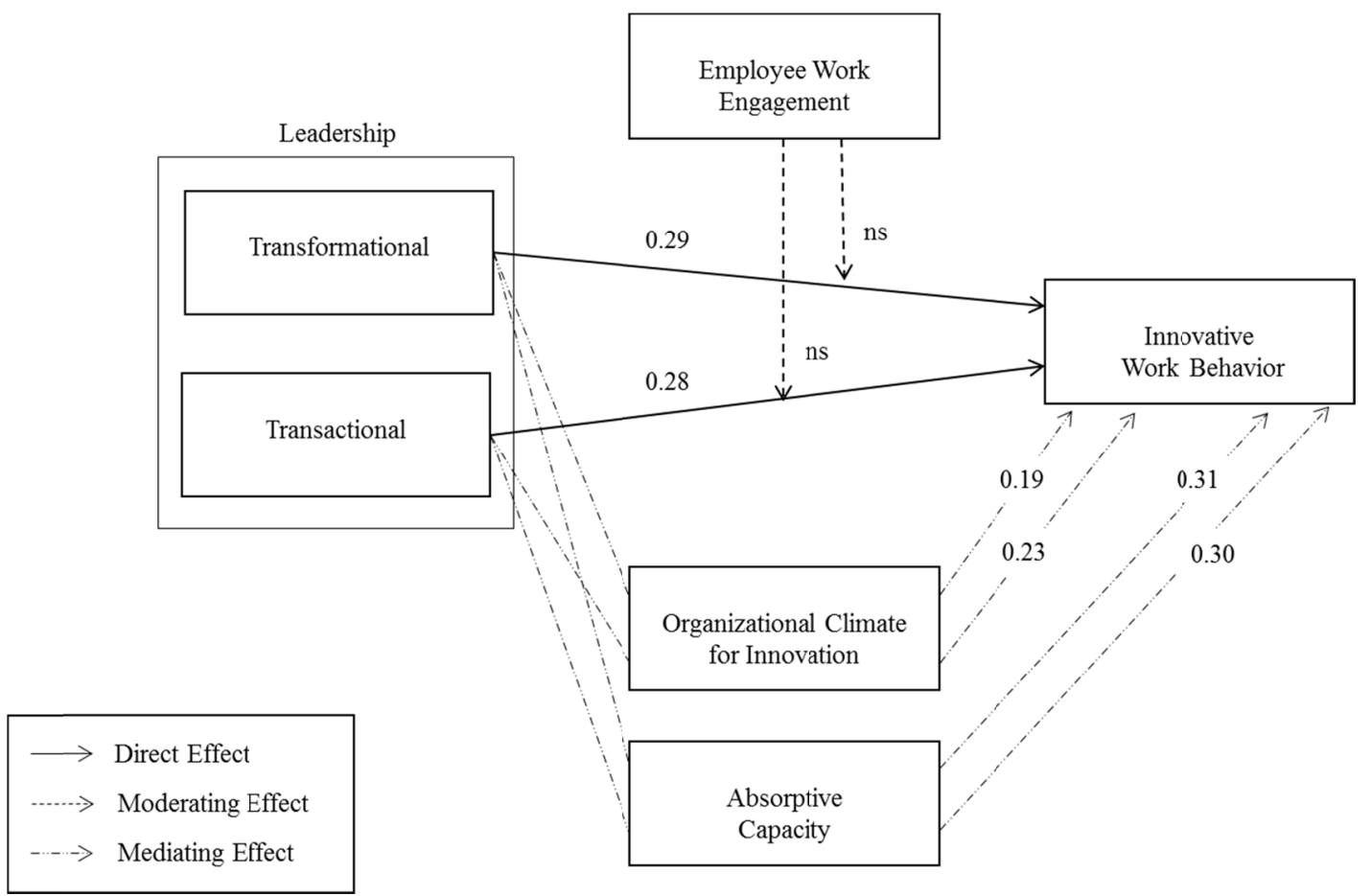

Figure 3. Findings of SEM and Regression Analyses of TFL and TSL as independent variables, IWB as dependent variable, EWE as moderator variable and both $\mathrm{OCI}$ and $\mathrm{AC}$ as mediator variables.

\section{Discussion}

The current study adds empirical evidence of the relationship between Transformational/Transactional leadership and Innovative work behavior as was suggested by Kahai et al. (2003) and Pieterse et al. (2010). The purpose was to test a mediator and moderator model, which included organizational and individual variables that have shown some linkage with our dependent variable, in this case, IWB.

Regarding leadership styles, we included two of the most studied models whose results had been inconclusive. As it was found previously by other authors (Afsar et al., 2014; Boerner et al., 2007; De Jong \& Den Hartog, 2007; Jung et al., 2003; Khan et al., 2012; Khaola \& Sephelane, 2013; Mumford et al., 2002; Pieterse et al., 2010; Waldman \& Bass, 1991) we corroborate the relationship between Transformational leadership and IWB. However, contrary to other authors' findings (Khaola \& Sephelane, 2013) and in the same line with Khan, et al. (2012) and Riaz (2009) the effect of transactional leadership on IWB does not show differences to that of transformational leadership: both of them exert quite similar influence of IWB. This result supports the idea that transactional leadership do not exert a negative influence on IWB. Moreover, some of its practices could be combined with transformational leadership to be more effective as has been suggested by other authors (Jung \& Sosik, 2002). In this order of ideas, transactional leadership might not be remarkably different from transformational as was postulated by Bass and Avolio. This topic related to IWB should be studied more deeply in subsequent researches.

Besides, the mediator effects of organizational climate for innovation and absorptive capacity were supported. This finding demonstrates how organizational characteristics have an important influence on employees' innovative behavior. This finding extends the literature about IWB, which had been scarcely studied (Damanpour \& Schneider, 2006). In the first case, organizational climate for innovation proves it exerts a mediator role for both leadership styles. It means, that it does not matter how people are encouraged to innovate, what is important is to create a positive environment where people could propose new things or new ways to deal with the organizational process. These finding suggest an important role of TFL/TSL for innovation by creating adequate conditions to express an innovative behavior (Judge et al., 1997; Übius, et al., 2013). Secondly, the absorptive capacity demonstrated to have a mediator role for transformational and transactional leadership. In both cases the effect was quite similar. This finding provides empirical evidence in a scarce field of knowledge, as was pointed out by Sattayaraksa \& Boonitt (2012). Our results correspond to those of Flatten, et al. (2015), a research where they found that both styles of leadership exert an important effect on IWB, but in different ways. We concluded as they suggested previously that both styles of leadership in a combined way could improve the absorptive capacity of the companies. Additionally, we provide evidence that the relationship between leadership 
and absorptive capacity influence, in an indirect way, the IWB as well.

Finally, we suggest that employees' work engagement, as mediator variable, could influence the relationship between both leadership styles and IWB. Contrary to our expectation, this individual variable does not exert a mediator role. However, the partial relationships among variables were confirmed: Leadership styles are directly related to work engagement, as was found by other authors (Zhu et al., 2009). Likewise, we corroborate the relationship between engagement and IWB as previously indicated by Schaufeli \& Bakker (2004) and Hakanen et al. (2008). It seems that employees' work engagement, as an individual variable, exerts a direct effect on IWB or as Gomes et al. (2015) affirm, a mediated effect. This finding supports the necessity to continue studying the role of work engagement on IWB and its relationship with leadership because, as Park et al. (2014) asserted, there is not enough empirical evidence that supports these relationships.

\section{Practical implications for management}

This study has several implications and provides both managerial and conceptual implications. For leaders and managers, these findings give a supported knowledge about how to lead to improve innovative behaviors in their employees, demystifying the overvaluation of transformational leadership as the best way to lead. This study corroborates that both styles of leadership involve practices that can encourage innovative work behaviors although in different ways. Even more, these results suggest that both styles combined might be more appropriate to increase this desirable behaviour in workers, something that should be addressed in further studies. Otherwise, this study shows the importance of providing an adequate organizational environment to individual innovation. Leadership practices influence organizational climate for creativity and this, in turn, has a positive linkage to employees' innovative behavior. Insofar as climate is a worker's perception, the effect of some leadership practices on climate could change according to culture, so it is important to replicate our proposed model in different countries. Likewise, this study shows that absorptive capacity, as an organizational variable is a very important factor to consider when a company wants to improve the innovative behavior. In this order of ideas, beyond the climate perception, an environment where the innovation is important makes people more likely to generate changes from their own position. Finally, this research indicates that individual characteristics as emotional involvement of workers is crucial to innovate, not as a moderator variable but in a direct way. We found a strong positive linkage between this emotional involvement towards work and individual innovation something that could be considered an exceptional performance in this challenging, changing and highly demanding and globalized world where companies operate. This study provides new empirical evidence to extend the literature in a scarce field of knowledge with important implications for the management area regarding the subject of organizational behavior.

\section{References}

Afsar, B. F., Badir, Y., \& Bin, B. (2014). Transformational leadership and innovative work behavior. Industrial Management \& Data Systems, 114(8), 1270-1300. https://doi.org/10.1111/j.1467-8691.2008.00487.x

Axtell, C., Holman, D., \& Wall, T. (2006). Promoting innovation: A change study. Journal of Organizational and Occupational Psychology, 79(3), 509-516. https://doi.org/10.1348/096317905X68240

Bass, B. M., \& Avolio, B. J. (2000). MLQ: Multifactor leadership questionnaire. Mind Garden.

Bass, B.M., \& Avolio, B.J. (1995). Multifactor Leadership Questionnaire. Redwood City, CA: Mind Garden.

Basu, R., \& Green, S. G. (1997). Leader-member Exchange and Transformational Leadership: An Empirical Examination of Innovative Behaviors in Leader-Member Dyads. Journal of Applied Social Psychology, 27(6), 477-99. https://doi.org/10.1111/j.1559-1816.1997.tb00643.x

Boerner, S., Eisenbeiss, S. A., \& Griesse, D. (2007). Follower behavior and organizational performance: The impact of transformational leaders. Journal of Leadership \& Organizational Studies, 13, 15-26. https://doi.org/10.1177/10717919070130030201

Camisón, C., \& Forés, B. (2010). Knowledge absorptive capacity: New insights for its conceptualization and measurement. Journal of Business Research, 63(7), 707-715. https://doi.org/10.1016/j.jbusres.2009.04.022

Chen, J., \& Chen, I. (2007). The relationships between personal traits, leadership styles, and innovative operation. Proceedings of the 13th Asia Pacific Management Conference, Melbourne, Australia, 420-425.

Cohen, W., \& Levinthal, D. (1990). Absorptive capacity: a new perspective on learning and innovation. Administrative Science Quarterly, 35(1), 128-152. https://doi.org/10.2307/2393553

Da Costa, S., Páez, D., Sánchez, F., Gondim, S., \& Rodríguez, M. (2014) Factores favorables a la innovación en las organizaciones: una integración de meta-análisis. Journal of Work and Organizational Psychology 30, 
67-74. https://doi.org/10.1016/j.rpto.2014.06.006

Damanpour, F., \& Schneider, M. (2006). Phases of adoption of innovation in organizations: Effects of environment, organization and top managers. British Journal of Management, 17, 215-236. https://doi.org/10.1111/j.1467-8551.2006.00498.x

De Jong, J. P., \& Den Hartog, D. N. (2008). Innovative work behavior: Measurement and validation. EIM Business and Policy Research, 1-27.

De Jong, J., \& Den Hartog, D. (2007). How leaders influence employees' innovative behavior. European Journal of innovation management, 10(1), 41-64. doi; 10.1108/14601060710720546

De Jong, J., \& Den Hartog, D. (2010). Measuring innovative work behaviour. Creativity and Innovation Management, 19(1), 23-36. https://doi.org/10.1111/j.1467-8691.2010.00547.x

De Rivera, J., \& Páez, D. (2007). Emotional climate, human security, and cultures of peace. Journal of social issues, 63(2), 233-253. https://doi.org/10.1111/j.1540-4560.2007.00506.x

De Spiegelaere, S., Van Gyes, G., De Witte, H., Niesen, W., \& Van Hootegem, G. (2014). On the relation of job insecurity, job autonomy, innovative work behavior and the mediating effect of work engagement. Creativity and Innovation Management, 23(3), 318-330. https://doi.org/10.1111/caim.12079

Dombrowski, C., Kim, J., Desouza, K., Braganza, A., Papagari, S., Baloh, P.(2007). Elements of innovative culture. Knowledge and Process Management, 14(3), 190-202. https://doi.org/10.1002/kpm.279

DuBrin, A. (2012). Leadership: Research Findings, Practice, and Skills. 7th ed. New York: Houghton Mifflin.

Farr, J., \& Ford, C. (1990). Individual innovation. In West, M. \& Farr, J. (Eds.), Innovation and creativity at work: Psychological and Organizational Strategies (pp. 63-80). Wiley: Chichester

Fay, D., Shippton, H., West, M. A., \& Patterson, M. (2015). Teamwork and organizational innovation: The moderating role of the HRM context. Creativity and Innovation Management, 24, 261-277.https://doi.org/10.1111/caim.12100

Flatten, T. C., Engelen, A., Zahra, S. A., \& Brettel, M. (2011). A measure of absorptive capacity: Scale development and validation. European Management Journal, 29(2), 98-116. https://doi.org/10.1016/j.emj.2010.11.002

Flatten, T. C., Greve, G. I., \& Brettel, M. (2011). Absorptive capacity and firm performance in SMEs: The mediating influence of strategic alliances. European Management Review, 8(3), 137-152. https://doi.org/10.1111/j.1740-4762.2011.01015.x

Flatten, T., Adams, D., \& Brettel, M. (2015). Fostering absorptive capacity through leadership: A cross-cultural analysis. Journal of World Business, 50, 519-534. https://doi.org/10.1016/j.jwb.2014.08.010

George, J. M., \& Zhou, J. (2002). Understanding when bad moods foster creativity and good ones don't: The role of context and clarity of feelings. Journal of Applied Psychology, 87, 687-697. http://dx.doi.org/10.1037/0021-9010.87.4.687

Gomes, C., Curral, L., \& Caetano, A. (2015). The mediating effect of work engagement on the relationship between self-leadership and individual innovation. International Journal of Innovation Management, 19(01), 1-18. https://doi.org/10.1142/S1363919615500097

González-Romá, V. (2008). La innovación en los equipos de trabajo. Papeles del psicólogo, 29(1), 32-40.

Guimaraes, T., Thielman, B., Guimaraes, V. C., \& Cornick, M. (2016). Absorptive capacity as moderator for company innovation success. International Journal of the Academic Business World, 10(2), 1-18

Gumusluoglu, L., \& Ilsev A. (2009). Transformational leadership, creativity and organizational innovation. Journal of Business Research, 62, 461- 473. https://doi.org/10.1016/j.jbusres.2007.07.032

Hair, J., Anderson, R., Tatham, R., \& Black, W. (1995). Multivariate data analysis. Englewood Cliffs: Prentice Hall.

Hakanen, J.J, Perhoniemi, R., \& Toppinen-Tanner, S. (2008). Positive gain spirals at work: From job resources to work engagement, personal initiative and work-unit innovativeness. Journal of Vocational Behavior, 73(1), 78-91. https://doi.org/10.1016/j.jvb.2008.01.003

Hartmann, A. (2006). The role of organizational culture in motivating innovative work behavior in construction organizations. Construction Innovation, 3(6), 159-172. https://doi.org/10.1108/14714170610710712 
Hoch, J. E. (2013). Shared leadership and innovation: The role of vertical leadership and employee integrity. Journal of Business and Psychology, 28(2), 159-174. Https://doi.org/10.1007/s10869-012-9273-6

Ismail, A., Mohamad, M. H., Mohamed, H. A., Rafiuddin, N. M., \& Zhen, K. W. P. (2010). Transformational and transactional leadership styles as a predictor of individual outcomes. Theoretical and Applied Economics, 6(6), 89-104

James, L. R., Choi, C. C., Ko, C. H., McNeil, P. K., Minton, M. K., Wright, M. A., \& Kim, K. I. (2008). Organizational and psychological climate: A review of theory and research. European Journal of Work and Organizational Psychology, 17(1), 5-32. http://dx.doi.org/10.1080/13594320701662550

Janssen, O. (2000). Job demands, perceptions of effort-reward fairness, and innovative work behavior, Journal of Occupational and organizational psychology, 73, 287-302. https://doi.org/10.1348/096317900167038

Janssen, O. (2005). The Joint Impact of Perceived Influence and Supervisor Supportiveness on Employee Innovative Behavior. Journal of Occupational and Organizational Psychology, 78(4). 573-579. https://doi.org/10.1348/096317905X25823

Judge, W. Q., Fryxell, G. E., \& Dooley, R. S. (1997). The new task of R\&D management: creating goal-directed communities for innovation. California Management Review, 39(3), 72-85.

Jung, D. I., \& Sosik, J. S. (2002). Transformational leadership in work groups: The role of empowerment, cohesiveness, and collective efficacy on perceived group performance. Small Group Research, 33(3), 313-336. https://doi.org/10.1177/10496402033003002

Jung, D. L., Chow, C., \& Wu, A. (2003). The Role of Transformational Leadership in enhancing Organization Innovation: Hypothesis and Some Preliminary Findings. The Leadership Quarterly, 14, 525-544. https://doi.org/10.1016/S1048-9843(03)00050-X

Jung, D., Wu, A., \& Chow, C.W. (2008). Towards understanding the direct and indirect effects of CEO' s transformational leadership on firm innovation. The Leadership Quarterly, 19, 582-594. https://doi.org/10.1016/j.leaqua.2008.07.007

Kahai, S. S., Sosik, J. J., \& Avolio, B. J. (2003). Effects of leadership style, anonymity, and rewards on creativity- relevant processes and outcomes in an electronic meeting system context. The Leadership Quarterly, 14, 499-524. https://doi.org/10.1016/S1048-9843(03)00049-3

Khan, M. J., Aslam, N., \& Riaz, M. N. (2012). Leadership styles as predictors of innovative work behavior. Pakistan Journal of Social and Clinical Psychology, 9(2), 17-22.

Khan, Z. A., Nawaz, D., \& Khan, I. (2015). The impact of leadership styles on innovation in health services. Gomal University Journal of Research, 31(1), 143-154.

Khaola, P. P., \& Sephelane, R. (2013). Leadership, organisational citizenship and innovative work behaviours in Lesotho: Exploratory evidence. Journal of Language, Technology \& Entrepreneurship in Africa, 4(2), 46-58.

Kim, S., \& Yoon, G. (2015). An Innovation-Driven Culture in Local Government Do Senior Manager's Transformational Leadership and the Climate for Creativity Matter?. Public Personnel Management, 44(2), 147-168. https://doi.org/10.1177/0091026014568896

King, N., \& Anderson, N. (2002) Managing Innovation and Change: A Critical Guide for Organizations. Thomson, London.

Macey, W. H., \& Schneider, B. (2008). The meaning of employee engagement. Industrial and Organizational Psychology, 1(1), 3-30. https://doi.org/10.1111/j.1754-9434.2007.0002.x

Martins, E. C., \& Terblanche, F. (2003). Building organizational culture that stimulates creativity and innovation. European Journal of Innovation Management, 6, 67-74. https://doi.org/10.1108/14601060310456337

Moilanen, M., Østbye, S., \& Woll, K. (2014). Non-R\&D SMEs: external knowledge, absorptive capacity and product innovation. Small Business Economics, 43(2), 447-462. https://doi.org/10.1007/s11187-014-9545-9

Mumford, M. D., Scott, G. M., Gaddis, B., \& Strange, J. M. (2002). Leading creative people: Orchestrating expertise and relationships. The leadership quarterly, 13(6), 705-750. https://doi.org/10.1016/S1048-9843(02)00158-3

Noblet, J., Simon, E., \& Parent, R. (2011). Absorptive capacity: a proposed operationalization. Knowledge Management Research \& Practice, 9 (4), 367-77. 
Park, Y.K., Song, J.H., Yoon, S.W., \& Kim, J. (2014). Learning organization and innovative behavior: The mediating effect of work engagement. European Journal of Training and Development, 38(1/2), 75-94. https://doi.org/10.1108/EJTD-04-2013-0040

Pieterse, A. N., van Knippenberg, D., Schippers, M., \& Stam, D. (2010). Transformational and transactional leadership and innovative behavior: The moderating role of psychological empowerment. Journal of Organizational Behavior, 31, 609-623. 609-623. https://doi.org/10.1002/job.650

Preacher, K. J., \& Hayes, A. F. (2004). SPSS and SAS procedures for estimating indirect effects in simple mediation models. Behavior Research Methods, Instruments, \& Computers, 36, 717-731.

Reichers, A., \& Schneider, B. (1990). Climate and culture: An evolution of constructs. In Schneider, B. (Ed.), Organizational climate and culture (pp.5-39). San Francisco:Jossey-Bass.

Riaz, M. N. (2009). Leadership styles as predictors of decision making styles (Unpublished M.Phil Thesis). National Institute of Psychology, Quaid-i-Azam University, Islamabad.

Runco, M. A. (2004). Creativity. Annual Review of Psychology, 55, 657-687. https://doi.org/10.1146/annurev.psych.55.090902.141502

Salanova, M., \& Schaufeli, W. B. (2008). A cross-national study of work engagement as a mediator between job resources and proactive behaviour. The International Journal of Human Resource Management, 19(1), 116-131. https://doi.org/10.1080/09585190701763982

Salanova, M., Agut, S., \& Peiro, J. M. (2005). Linking organizational resources and work engagement to employee performance and customer loyalty: The mediation of service climate. Journal of Applied Psychology, 90(6), 1217-1227. https://doi.org/10.1037/0021-9010.90.6.1217

Sattayaraksa, T., \& Boonitt, S. (2012) Leadership as a determinant of product innovation: a systematic review of the literature. Proceedings of 2012 IEEE International Conference on Industrial Engineering and Engineering Management, Hong Kong.

Schaufeli, W, M Salanova, M., González-Romá, V., \& Bakker, B.A (2002). The measurement of engagement and burnout: A two sample confirmatory factor analytic approach. Journal of Happiness Studies, 3(1), 71-92.

Schaufeli, W. B., \& Bakker, A. B. (2004). Job demands, job resources, and their relationship with burnout and engagement: a multi-sample study. Journal of Organizational Behavior, 25(3), 293-315. https://doi.org/10.1002/job.248

Scott, S. G., \& Bruce, R. A. (1994). Determinants of innovative behavior: a path model of individual innovation in the workplace. Academy of Management Journal, 37, 580-607.

Shafie, S. B., Siti-Nabiha, A. K., \& Tan, C. L. (2014). Organizational culture, transformational leadership and product innovation: a conceptual review. Organizational Innovation Strategies, 7, 30-43

Shalley, C.E., \& Gilson, L.L. (2004). What leaders need to know: a review of social and contextual factors that can foster or hinder creativity. The Leadership Quarterly, 15(1), 33-53. https://doi.org/10.1016/j.leaqua.2003.12.004

Shin, S. J., \& Zhou, J. (2003). Transformational leadership, conservation, and creativity: Evidence from Korea. Academy of management Journal, 46(6), 703-714.

Siegel, S., \& Kaemmerer, W. (1978). Measuring the perceived support for innovation in organizations. Journal of Applied Psychology, 63, 553-562.

Subramaniam, M., \& Youndt, M. A. (2005). The influence of intellectual capital on the types of innovative capabilities. Academy of Management Journal, 48, 450-463.

Teece, D., Pisano, G., \& Shuen, A. (1997). Dynamic capabilities and strategic management. Strategic Management Journal, 18(7), 509-533.

Thakur, R., Hsu, S. H., \& Fontenot, G. (2012). Innovation in healthcare: Issues and future trends. Journal of Business Research, 65(4), 562-569. https://doi.org/10.1016/j.jbusres.2011.02.022

Übius, Ü., Alas, R., \& Elenurm, T. (2013). Impact of innovation climate on individual and organisational level factors in Asia and Europe. Journal of Business Economics and Management, 14(1), 1-21. http://dx.doi.org/10.3846/16111699.2011.642081

Waldman, D. A., \& Bass, B. M. (1991). Transformational leadership at different phases of the innovation process. Journal of High Technology Management Research, 2, 169-180. 
https://doi.org/10.1016/1047-8310(91)90002-6

West, M. A., \& Wallace, M. (1991). Innovation in Health Care Teams. European Journal of Social Psychology, 21(4), 303-15. https://doi.org/10.1002/ejsp.2420210404

Yeoh, K. K., \& Mahmood, R. (2013). The relationship between pro-innovation organizational climate, leader-member exchange and innovative work behavior: A study among the knowledge workers of the knowledge-intensive business services in Malaysia. Business Management Dynamics, 2(8), 15-30.

Zahra, S., \& George, G. (2002). Absorptive capacity: A review, reconceptualization, and extension. Academy of Management Review, 27(2), 185-203.

Zhou, J., \& Shalley, C. E. (2003). Research on employee creativity: a critical review and directions for future research. Research in Personal and Human Resource Management. 22, 165-217.

Zhu, W., Avolio, B. J., \& Walumbwa, F. O. (2009). Moderating role of follower characteristics with transformational leadership and follower engagement. Group \& Organization Management, 34, 590-619. https://doi.org/10.1177/1059601108331242

\section{Copyrights}

Copyright for this article is retained by the author(s), with first publication rights granted to the journal.

This is an open-access article distributed under the terms and conditions of the Creative Commons Attribution license (http://creativecommons.org/licenses/by/4.0/). 